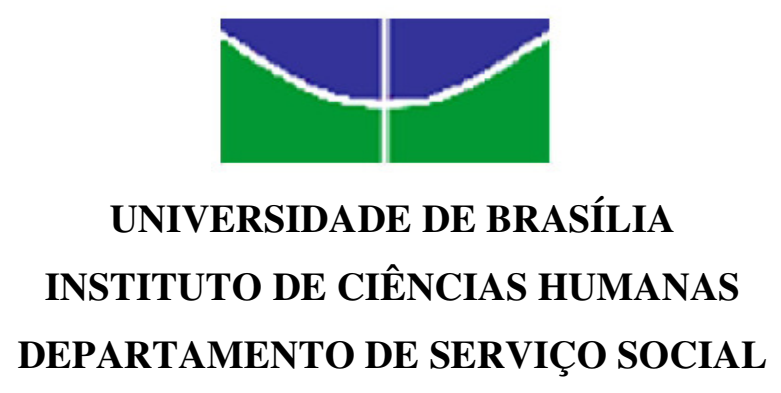

Wênia Cristian de Oliveira

O ENVELHECIMENTO NAS PUBLICAÇÕES DO SERVIÇO SOCIAL:

UMA ANÁLISE A PARTIR DOS ARTIGOS PUBLICADOS NA REVISTA SERVIÇO SOCIAL \& SOCIEDADE

Brasília (DF), julho de 2008. 


\title{
O ENVELHECIMENTO NAS PUBLICAÇÕES DO SERVIÇO SOCIAL: UMA ANÁLISE A PARTIR DOS ARTIGOS PUBLICADOS NA REVISTA SERVIÇO SOCIAL \& SOCIEDADE
}

\author{
Monografia apresentada ao Departamento \\ de Serviço Social para obtenção do \\ diploma de graduação em Serviço Social, \\ sob orientação da Prof. ${ }^{a}$ Ms. Patrícia \\ Cristina Pinheiro de Almeida.
}

Brasília (DF), julho de 2008. 
Dedico esta monografia à minha família pelo carinho e apoio que me deram em todas as fases da minha vida. 


\section{Agradecimentos}

À professora Patrícia Cristina Pinheiro de Almeida pelo carinho e orientação dispensados neste trabalho.

Ao professor Mário Ângelo Silva e à assistente social Kelly Cristina Tavares, pela disponibilidade em participar da banca de minha monografia.

Aos professores do Departamento de Serviço Social pelo aprendizado por eles proporcionado.

Aos funcionários do Departamento de Serviço Social pela prontidão na solução dos meus assuntos acadêmicos.

Às assistentes sociais, Karolina V. C. Varjão, Maria Cristina Viana, Mônica Mary Sbabo e Nadja Maria Oliveira da Silva pelo aprendizado proporcionado em meus estágios.

Aos meus amigos, de modo especial à Flávia Squinca, à Thaís Kristosch Imperatori, e à Vanessa de Sousa Nascimento. 
"Ninguém fica velho simplesmente porque viveu alguns anos. A pessoa só envelhece quando abandona seus ideais... Você é tão jovem quanto sua autoconfiança, tão idoso quanto seu medo, tão moço quanto suas esperanças, e tão velho quanto o seu desespero. No centro de todo coração, há um gravador; enquanto ele receber mensagens de beleza, esperança, alegria e coragem, você permanece jovem. Quando os fios se romperem, e seu coração estiver coberto com as neves de pessimismo e o gelo do ceticismo, então, e só então você terá ficado velho..."

\section{Douglas MacArthur}




\section{Resumo}

O tema envelhecimento apresenta uma nova realidade no contexto brasileiro que demanda novas formas de intervenção do Estado e da sociedade. No campo do Serviço Social, a temática do envelhecimento é abordada relacionada às expressões da questão social e exige qualificações diferenciadas na atuação com políticas sociais, particularmente, a seguridade social. A presente monografia buscou conhecer como o campo envelhecimento se expressa dentro da publicação científica do Serviço Social, a partir da análise dos artigos publicados na revista Serviço Social \& Sociedade, no período de 1979 a 2008. A análise dos artigos encontrados aponta que as publicações sobre envelhecimento no Serviço Social são eminentemente produzidas por autores do sexo feminino, com vínculo em universidades confessionais católicas da região Sudeste. Percebe-se que há uma descontinuidade nas publicações demonstrando que esse tema ainda não está enraizado na produção de conhecimento do Serviço Social.

Palavras-chave: Envelhecimento, Publicação, Serviço Social. 


\section{Lista de quadros e gráficos}

Quadro 1 - Temática abordada na revista Serviço Social \& Sociedade no período de 1979 a 1989

Quadro 2 - Temática abordada na revista Serviço Social \& Sociedade na década de $1990 \quad 21$

Quadro 3 - $\quad$ Temáticas específicas abordadas nas revistas $n^{\circ} 50$ a ${ }^{\circ} 93 \quad 22$

Quadro 4 - Autores dos artigos pesquisados na Revista Serviço Social \& Sociedade 25

Quadro 5 - Formação acadêmica e pós-graduação dos autores dos artigos pesquisados na Revista Serviço Social \& Sociedade 26

Quadro 6 - Vínculo institucional e região dos autores dos artigos pesquisados na Revistas Serviço Social \& Sociedade

Quadro 7 - Artigos pesquisados com número da Revista Serviço Social \& Sociedade e ano de publicação

Quadro 8 - Temas dos números das revistas Serviço Social \& Sociedade com artigos publicados sobre envelhecimento

Quadro 9 - Palavras-chave dos artigos pesquisados na Revista Serviço Social \& Sociedade 30

Gráfico 1 - Palavras-chave com maior freqüência nos artigos pesquisados na Revista Serviço Social \& Sociedade

Quadro 10 - Metodologia utilizada nos artigos pesquisados na Revista Serviço Social \& Sociedade 


\section{Sumário}

Introdução

Capítulo 1. Contextualizando o envelhecimento 13

1.1. O conceito de envelhecimento 13

$\begin{array}{ll}\text { 1.2. O envelhecimento brasileiro } & 14\end{array}$

$\begin{array}{lr}\text { Capítulo 2. Metodologia } & 18\end{array}$

$\begin{array}{ll}\text { 2.1. Etapas de realização da pesquisa } & 18\end{array}$

2.2. Apresentação da Revista Serviço Social \& Sociedade 19

Capítulo 3. Apresentação e análise dos dados 24

3.1. Sobre os autores $\quad 25$

3.1.1. Formação acadêmica e pós-graduação 25

3.1.2. Vínculo institucional e região dos autores 27

3.2. Sobre os artigos 28

3.2.1. Artigos, número da revista e ano de publicação 28

$\begin{array}{ll}\text { 3.2.2. Tema das revistas } & 29\end{array}$

3.2.3. Palavras-chave $\quad 30$

3.2.4. Metodologia utilizada nos artigos $\quad 32$

3.2.5. Artigos publicados por assistentes sociais 33

3.2.6. Saúde, previdência e assistência social 35

3.2.7. Envelhecimento e Revista Serviço Social \& Sociedade 35

$\begin{array}{ll}\text { Considerações finais } & 37\end{array}$

$\begin{array}{ll}\text { Referências Bibliográficas } & 39\end{array}$

$\begin{array}{ll}\text { Anexos } & 41\end{array}$

Anexo 1 - Roteiro de análise dos artigos da Revista Serviço Social \& Sociedade $\quad 41$

Anexo 2 - Resumo dos artigos pesquisados 43 


\section{Introdução}

A questão social é terreno fértil que estabelece variados objetos de estudo e intervenção do Serviço Social enquanto especialização do trabalho. O assistente social atua nas relações sociais cotidianas, no atendimento às variadas expressões da questão social, tais como as vivenciadas pelos indivíduos sociais na família, no trabalho, na assistência social, na saúde, na previdência social, na habitação, na educação, dentre outras.

As lutas sociais romperam com o domínio privado nas relações entre capital e trabalho, configurando o debate sobre a questão social na esfera pública. Os conflitos sociais passam a exigir a interferência do Estado no reconhecimento e na legalização de direitos e deveres dos sujeitos sociais envolvidos, consubstanciados nas políticas e serviços sociais (IAMAMOTO, 2007).

$\mathrm{Na}$ sociedade burguesa o envelhecimento populacional acaba por colocar-se de forma problemática na ordem do capitalismo, em função da lógica que este engendra na reprodução das relações sociais de produção. O fenômeno do envelhecimento é um tema multidisciplinar que perpassa várias políticas públicas onde os assistentes sociais atuam como: assistência social, saúde, previdência social. Pereira (2005) destaca três evidências que estimulam o interesse dos cursos de Serviço Social pelo fenômeno do envelhecimento:

- O fato do progressivo envelhecimento da população ser um fenômeno sócio político inédito e sustentado, que produziu a partir do último quarto do século $\mathrm{XX}$, o interesse pelos assuntos gerontológicos tornando-se, pela primeira vez na história da humanidade, tão relevante, ao ponto de superar o domínio dos assuntos relacionados à infância e à adolescência, que predominou por mais da metade daquele século;

- O aparecimento de novas demandas derivadas do fenômeno do envelhecimento e das condições estruturais e históricas em que esse fenômeno é produzido remete ao entendimento de que essas demandas se referem não só à dimensão biológica, mas também psicológica, econômica, social e de cidadania das pessoas idosas;

- A constatação de que as políticas, os serviços, as instituições e os agentes de proteção social convencionais não mais respondem de maneira adequada a essas 
novas demandas, tornando necessária a revisão dos compromissos com o bem-estar dessa parcela da população, tanto por parte do Estado quanto da sociedade.

Apesar dessas evidências, no período de 2001 a 2003, dentre 719 projetos de pesquisa no âmbito dos programas de Pós-Graduação do Serviço Social, apenas dois projetos foram na área de transição demográfica e processo de envelhecimento. Um sobre ações investigativas, intercâmbio e sistematização de conhecimentos na área de envelhecimento humano na Amazônia, e o outro sobre processos de aposentadoria e sua relação com o envelhecimento e o papel do assistente social frente a esta demanda contemporânea da sociedade (CARVALHO \& SILVA, 2005).

Tendo em vista que a produção científica subsidia a prática profissional, é por meio dela que se promove e fomenta um debate contínuo e profundo sobre o tema, possibilitando sua conceituação, o conhecimento da sua realidade e seus desafios, assim como a proposição de formas de enfrentamento da problemática relacionada ao tema. Por esse motivo torna-se necessário verificar em que medida o fenômeno do envelhecimento populacional brasileiro está tendo visibilidade na comunidade acadêmica do Serviço Social.

A presente monografia busca compreender como o processo do envelhecimento se expressa dentro do Serviço Social e do seu campo teórico a partir da seguinte pergunta: "Como o tema envelhecimento se expressa nas publicações do Serviço Social?". Dessa forma o objeto de estudo foi o tratamento do tema envelhecimento populacional na literatura do Serviço Social. Para essa análise, foi escolhida a Revista Serviço Social \& Sociedade, dentre os vários periódicos publicados nessa área do conhecimento devido a sua ampla divulgação entre os acadêmicos e profissionais, bem como pela sua consolidação, uma vez que, em quase três décadas já foram publicados mais de 550 artigos.

O interesse pela produção do conhecimento do Serviço Social a respeito de determinadas temáticas já foi expresso em algumas monografias produzidas por alunos do curso de Serviço Social da Universidade de Brasília:

- Produção do conhecimento no Serviço Social: Uma análise comparativa de dois autores - Marcelo Emmanuel dos Santos, 1993.

- A produção do conhecimento do Serviço Social sobre Assistência Social.- Tatyane de Camargo Aranha, 2003. 
- A produção de conhecimento do Serviço Social sobre o Meio Ambiente (20002004) - Daiane Souza Guedes, 2005.

- O campo de estudo de gênero no Serviço Social a partir de análise das publicações na Revista Serviço Social \& Sociedade - Lívia Barbosa Pereira, 2006.

- Gênero e Serviço Social: uma análise da produção bibliográfica do CBAS e do ENPESS (2000-2004) - Juliana Maria Alves de Moraes Brito, 2007.

- Produção teórica do Serviço Social: análise de alguns estudos sobre Seguridade Social - Thaís Neves de Menezes Costa, 2007.

A pesquisa que fundamenta essa monografia partiu da hipótese de que há uma lacuna no debate sobre envelhecimento no Serviço Social e teve como objetivo contribuir para um melhor conhecimento da produção científica do Serviço Social. Foram analisados todos os artigos na Revista Serviço Social \& Sociedade, que tratam da questão do envelhecimento no período de 1979 a 2008. Tendo sido encontrados 15 artigos sobre esta temática. Espera-se que os resultados possibilitem um mapeamento do campo do envelhecimento no Serviço Social, podendo contribuir para o fomento de pesquisas e conseqüentemente para consolidação do campo.

A monografia está estruturada em três capítulos. No primeiro capítulo é apresentada a contextualização do fenômeno envelhecimento. Primeiramente é apresentado o conceito de envelhecimento segundo alguns autores de diferentes áreas do conhecimento. Em seguida, é apresentado um breve panorama sobre envelhecimento brasileiro e as políticas sociais voltadas para os idosos.

O segundo capítulo apresenta a metodologia e os procedimentos realizados na pesquisa. Como foi mencionado anteriormente, trata-se de um estudo exploratório do tema envelhecimento na revista Serviço Social \& Sociedade no período de 1979 a 2008. Para a realização dessa pesquisa utilizou-se metodologia qualitativa para a coleta e análise dos dados, sendo estudados tanto o conteúdo dos artigos como o perfil dos autores. Os dados foram tabulados em formulário próprio elaborado ao longo da pesquisa. 
No terceiro capítulo são apresentados os principais resultados da pesquisa. Este capítulo foi subdividido em duas seções: sobre os autores e sobre os artigos. Na seção sobre os autores são apresentados dados referentes à região, ao vinculo institucional e à formação acadêmica dos autores. Na seção sobre os artigos são apresentadas a metodologia utilizada, as palavras-chave e as temáticas mais recorrentes nos artigos.

No último capítulo são apresentadas as principais conclusões e evidências encontradas na pesquisa. $\mathrm{O}$ estudo mostrou que o campo envelhecimento ainda não está enraizado na produção do conhecimento científico do Serviço Social. Algumas hipóteses para essa não discussão são: a recente inserção dessa área como campo de atuação do Serviço Social e a escassez de pesquisas sobre o tema. 


\title{
Capítulo 1
}

\section{Contextualizando o envelhecimento}

\section{1 - O Conceito de envelhecimento}

O processo de envelhecimento é vivenciado de forma diferente pelas pessoas, apesar de haver semelhanças nesse processo, como, por exemplo, as perdas orgânicas. As diferenças são devidas às características genéticas, históricas, psicológicas e sociais que influenciam as pessoas durante a sua vida. $\mathrm{O}$ conceito que se tem dos velhos vem sendo modificado através dos séculos, mas a desvalorização acarretada pela idade esteve presente em todos os contextos e períodos.

Não há um consenso quanto ao início da velhice.

\begin{abstract}
"Não é possível estabelecer conceitos universalmente aceitáveis e uma terminologia globalmente padronizada para o envelhecimento. Inevitavelmente, há conotações políticas e ideológicas associadas ao conceito, que pode ser melhor visualizado dentro de sociedades específicas"(VERAS, 2003).
\end{abstract}

O envelhecimento é um processo universal que ocasiona uma maior fragilidade ao organismo e por consequiência a diminuição gradual da sobrevivência. No entanto, isso não significa que seja sinônimo de doença, tendo em vista que apenas uma minoria dos seres humanos tem uma velhice patológica, com independência limitada. (DE VITTA, 2000).

De acordo com Papaléo Netto (2002), o envelhecimento é um processo dinâmico e progressivo, que tem seu início na concepção e seu fim com a morte. No entanto, para Guimarães (1999), o envelhecimento começa quando o organismo começa a apresentar perdas orgânicas, por volta dos 30 anos de idade. Já outros autores afirmam que esse processo somente tem início nos anos tardios de vida.

De acordo com Camarano (1999) a velhice inclui populações com características muito diferentes, uma vez que abrange pessoas desde os 60 anos até centenários. Isso dificulta a formulação de políticas públicas para essa população, visto que as demandas são diferenciadas. Veras (1994) observa a complexidade dessa população e divide o envelhecimento em três sub-faixas etárias para observar e comparar as suas diferenças e 
similaridades: idosos jovens - 60 a 69 anos; meio - idosos - 70 a 79 anos; e idosos velhos - acima de 80 anos.

Bacelar (2002) concebe o envelhecimento sobre duas perspectivas: a do tempo interior e a do tempo exterior. Na primeira, à medida que se envelhece, são possíveis diversas saídas para os impasses e desafios da existência. O envelhecer pode ser considerado pela pessoa como um período de perdas e limitações, ou como um tempo em que é possível enriquecer-se com as experiências. Na outra perspectiva, envelhecer é desgastar-se, perder o vigor físico, é um processo irreversível.

A Organização Mundial de Saúde estipulou a idade de 60 anos para marcar o início da velhice em países em desenvolvimento, e 65 anos, em países desenvolvidos, pelo fato de nessas idades acentuarem-se as transformações biológicas e ocorrer o afastamento do mundo do trabalho (MASCARO, 1997). O Brasil adotou, a partir do Estatuto do Idoso, a idade de 60 anos para a classificação dos idosos:

“Art. $1^{\mathrm{o}}$ É instituído o Estatuto do Idoso, destinado a regular os direitos assegurados às pessoas com idade igual ou superior a 60 (sessenta) anos" (Brasil, 2003).

Na contemporaneidade há uma tendência a pensar que a velhice pode ser um momento para novas conquistas, aliadas as experiências vividas e aos saberes acumulados. Trata-se de uma revisão da visão conservadora que teve início a partir da segunda metade do século XIX que tratava a velhice, como uma fase de declínio físico e de ausência de papéis sociais. Debert (1999) afirma que esta visão conservadora foi responsável por um conjunto de imagens negativas associada à velhice, porém, ela foi fundamental para a legitimação dos direitos sociais, como a universalização da aposentadoria.

As definições de envelhecimento englobam diferentes aspectos: biológicos, psicológicos, sociais e culturais, o que expressa um conceito multifatorial. Essa perspectiva possibilita entender que embora o envelhecimento seja uma realidade mundial, não ocorre de forma igual em todas as pessoas, e nem em todas as culturas e países. A relação entre envelhecimento e saúde pode ser questionada porque, apesar de existirem doenças específicas deste grupo etário, não é possível estabelecer que todos os idosos são ou serão doentes. 


\section{2 - O envelhecimento brasileiro}

A população brasileira tem aumentado rapidamente, principalmente na faixa etária a partir dos 60 anos devido à associação da redução da fecundidade com a queda da mortalidade. Segundo a OMS (2005), no período de 1950 a 2025, o grupo de idosos no Brasil deverá ter aumentado em quinze vezes, enquanto a população total em cinco. No mesmo período, os idosos dos Estados Unidos, Japão e China, estarão crescendo respectivamente, apenas 3,5, 5 e 6,5 vezes. Isso porque o processo de envelhecimento ocorreu de forma distinta entre os países desenvolvidos e os em desenvolvimento. Enquanto nos países desenvolvidos esse processo ocorreu de forma gradual, nos em desenvolvimento este processo foi marcado pela rapidez do aumento absoluto e relativo da população idosa. Até 1960, todos os grupos etários registravam crescimento quase igual. No entanto, a partir dessa década a população idosa passou a crescer rapidamente em relação aos demais grupos (VERAS, 2003).

Os estados do Rio de Janeiro, Rio Grande do Sul e Paraíba possuem o maior percentual de idosos e Roraima, Amapá e Amazonas o menor percentual. Dentre os idosos, 81,2\% reside em área urbana (BERZINS, 2003). Foi verificado no Censo 2000 que $62,4 \%$ dos idosos brasileiros eram responsáveis pelos domicílios. Em muitas cidades, principalmente no Nordeste, o dinheiro da aposentadoria é uma das principais fontes de arrecadação dos municípios e manutenção das famílias. Ainda de acordo com esse Censo, havia 5,1 milhões de idosos analfabetos em 2000 (IBGE 2000).

O número de idosos vivendo sozinho é crescente. A universalização do direito a Seguridade Social estabelecido na Constituição de 1988, as melhorias nas condições de saúde e outros avanços tecnológicos, tais como nos meios de comunicação, elevadores, automóveis, entre outros, podem estar sugerindo que viver só, para os idosos, representa mais formas inovadoras e bem-sucedidas de envelhecimento do que de abandono, descaso e/ou solidão, conforme têm mostrado pesquisas recentes (DEBERT, 1999 apud CAMARANO, 2002).

No Brasil, os homens vivem em média 65 anos, e as mulheres, 72,8 anos, isso representa quase oito anos a mais. Em 2000, 55\% da população idosa era de mulheres (IBGE, 2000). Este fenômeno é conhecido como "feminização da velhice" e pode estar relacionado a diferenças na exposição a riscos no trabalho e a mortes por acidentes. Além disso, as mulheres são mais cautelosas com sua saúde. Essa questão tem recebido 
bastante atenção devido as suas implicações em termos de políticas públicas, tendo em vista que a maioria das mulheres idosas são viúvas, vivem sozinhas, não possuem experiência de trabalho no mercado formal e apresentam baixo ou nenhum nível de escolaridade. Além disso, nem sempre a maior longevidade feminina é vista como vantagem, pois, isso faz com que elas passem pela experiência de debilitação biológica devido a doenças crônicas, enquanto os homens morrem antes (NOGALES, 1998 apud CAMARANO, 2002).

A primeira iniciativa em nível Federal destinada para os idosos no Brasil ocorreu em 1974 (CAMARANO \& PASINATO, 2004). Tratou-se do estabelecimento de uma Renda Mensal Vitalícia, que garantia um benefício correspondente a meio salário mínimo a todas as pessoas com mais de 70 anos de idade que não recebiam beneficio algum da Previdência Social e que não apresentavam condições de subsistência.

Em 1975, foi criada a Lei 6.334 que regulava a situação dos aposentados pela previdência social e do segurado que a ela se vinculava após completar 60 anos. Com o objetivo de conhecer a realidade dos idosos brasileiros, o Ministério da Previdência e Assistência Social realizou, em 1976, com a colaboração do SESC/SP, três seminários regionais: Belo Horizonte, Fortaleza e São Paulo. As conclusões obtidas nesses três seminários motivaram a realização de um quarto, só que em nível federal, denominado Seminário Nacional sobre Política Social da Velhice, que deu origem à Política Social da Velhice, originando o documento "Política Social para o Idoso - Diretrizes Básicas" (COSTA, MENDONÇA e ABIGALIL, 2002).

A inserção da temática do idoso nas pautas legais deve-se também a Constituição da República Federativa do Brasil de 1988, nos artigos 14, 153, 203, 229, e 230. Ela possibilitou que a temática começasse a fazer parte do discurso da democracia e do acesso universal aos serviços, destacando-se em relação às demais Constituições brasileiras, por inserir nestes artigos a questão da aposentadoria; a família, a sociedade e o Estado, estes três últimos como protagonistas na defesa dos direitos dos idosos (BRASIL, 1988).

“Art. 230. A família, a sociedade e o Estado têm o dever de amparar as pessoas idosas, assegurando sua participação na comunidade, defendendo sua dignidade e bem-estar e garantindo-lhes o direito à vida". 
$\S 1^{\circ}$ - Os programas de amparo aos idosos serão executados preferencialmente em seus lares.

$\S 2^{\circ}$ - Aos maiores de sessenta e cinco anos é garantida a gratuidade dos transportes coletivos urbanos" (BRASIL, 1988).

A Lei Orgânica da Assistência Social - Lei 8.742/93, que regulamentou a política de assistência social brasileira, prevê aos idosos: proteção à velhice por meio da garantia de um salário mínimo mensal por meio do Benefício de Prestação Continuada, de acordo com o critério de renda. Esse benefício é destinado ao idoso com 65 anos ou mais que comprove não possuir recursos para prover seu próprio sustento, nem de tê-lo provido por sua família (BRASIL, 1993).

A criação da Política Nacional do Idoso - PNI, em 1994, foi o marco legal da proteção ao idoso no Brasil. Esta política estabeleceu que é dever da família, da sociedade, e do Estado, assegurar os direitos de cidadania do idoso, garantir sua participação na comunidade, defender sua dignidade, seu bem-estar e o seu direito à vida (BRASIL, 1994).

A Lei $n^{\circ} 10.741$, denominada Estatuto do Idoso, entrou em vigor no dia 01 de outubro de 2003, Dia Internacional do Idoso (BRASIL, 2003). Esse estatuto representa um grande avanço em termos de garantias legais para o idoso em nosso país, sendo bem mais abrangente que a PNI e a própria Constituição Federal de 1988, instituindo penas severas a quem desrespeitar o idoso, facilitando a atuação do Ministério Público no enfrentamento ao abandono, ao abuso, à agressão e à violência contra os idosos. Isso foi a maior novidade advinda com o Estatuto do Idoso. Além disso, com este Estatuto, foram determinados aos Conselhos (Nacional, Estadual e Municipal) o acompanhamento e o zelo para que sejam cumpridos os direitos do idoso. No entanto, apesar dos avanços conquistados por meio do Estatuto do Idoso, há ainda o grande desafio da materialização desses direitos por ele preconizados. 


\section{Capítulo 2}

\section{Metodologia}

O presente estudo é uma pesquisa qualitativa, de caráter documental e de cunho exploratório, com o objetivo de demonstrar a expressão do campo envelhecimento nas publicações do Serviço Social, que utilizou como fonte de dados a revista Serviço Social \& Sociedade. A pesquisa qualitativa privilegia o entendimento de determinada situação ou fenômeno social, se preocupando com aspectos que não podem ser quantificados, em especial nas Ciências Sociais. Isso significa trabalhar com significados, motivos, aspirações, crenças, valores e atitudes dos sujeitos envolvidos no processo de pesquisa, de modo a observar a singularidade do fenômeno social e sua complexidade (MINAYO, 2007). Este capítulo dedica-se às etapas de realização da pesquisa e seu objeto de estudo.

\subsection{Etapas de realização da pesquisa}

Sendo a metodologia o caminho e a forma de abordagem da realidade durante uma pesquisa científica, inclui a teoria de abordagem sobre o tema (método), os instrumentos de operacionalização do conhecimento (técnicas) e a criatividade do pesquisador (sua experiência, capacidade e sensibilidade) (MINAYO, 2007). A presente pesquisa foi composta das seguintes etapas:

- Levantamento bibliográfico sobre envelhecimento com o objetivo de buscar literatura acerca do tema, de modo conhecer a realidade deste campo no Brasil e no mundo, além de conceitos importantes, principais desafios, principais autores e grupos de pesquisa nessa área. Nessa etapa foram utilizados os recursos disponíveis na Biblioteca Central da Universidade de Brasília e nas bases de dados Scielo (http://www.scielo.br/) e Portal de Periódicos da CAPES (http://www.periodicos.capes.gov.br/).

- Elaboração do projeto de pesquisa contendo pergunta-chave da pesquisa, hipótese, objetivos, metodologia, justificativa, cronograma e referências de acordo com as normas propostas na disciplina Projeto de Trabalho de Conclusão de Curso. 
- Elaboração do instrumento de coleta de dados. Foi elaborada uma ficha para guiar a busca dos dados nos artigos ${ }^{1}$. Esta ficha contém questões relacionadas aos artigos e aos autores. Em relação aos artigos as questões buscam conhecer os temas e palavras-chave mais recorrentes. É importante lembrar que somente a partir de 1996 começaram a ser publicadas revistas com temas específicos e que os artigos começaram a conter palavras-chave somente em 2003. Além disso, buscou-se conhecer a metodologia utilizada no artigo. No entanto, em alguns artigos os autores não apresentaram a metodologia para realização de sua pesquisa. Em relação aos autores, as questões buscaram conhecer a região do país, o vínculo institucional e a formação acadêmica.

- Leitura e seleção dos artigos. Primeiramente, foram pesquisados todos os números editados da revista Serviço Social \& Sociedade, ou seja, todas as revistas de 1979 a 2008, da $n^{\circ} 1$ à $^{\circ}$ 93. Em um segundo momento, iniciou-se a busca por artigos em cujo título constava as palavras: envelhecimento, idoso, gerontologia, terceira-idade, velhice, velho, aposentadoria. Foram encontrados 15 artigos. Em seguida, foi realizada a leitura e a análise desses artigos selecionados, utilizando a ficha para coleta dos dados.

- Coleta de dados dos autores. O levantamento dos dados referentes aos autores dos artigos selecionados foi realizado por meio da busca do currículo lattes desses autores na Plataforma Lattes do Conselho Nacional de Desenvolvimento Científico e Tecnológico - CNPq (http://lattes.cnpq.br). É importante ressaltar que oito autoras não possuíam cadastro na Plataforma Lattes, o que dificultou a coleta de dados.

- Leitura e análise qualitativa dos dados levantados. Essa etapa teve o objetivo de refletir sobre os dados obtidos a partir dos objetivos da pesquisa e da revisão bibliográfica (CRESWELL, 2007).

\subsection{Apresentação da Revista Serviço Social \& Sociedade}

O primeiro número da Revista Serviço Social \& Sociedade foi editado em setembro de 1979. Atualmente, a revista encontra-se no número 93, editado em março de 2008. Nesses quase trinta anos da revista já foram publicados mais de 550 artigos, o

\footnotetext{
O instrumento de coleta de dados encontra-se em anexo.
} 
que mostra a relevância deste periódico para a produção científica do Serviço Social no Brasil.

As contribuições da revista podem ser assim resumidas:

"fundamentar e instrumentalizar a ação profissional crítica na academia, na organização político-profissional, na prática institucional e junto aos movimentos sociais populares; contribuir para o avanço teórico-metodológico no campo do trabalho social; fomentar o avanço da produção científica do Serviço Social e sua difusão" (SILVA, 1999).

O quadro a seguir mostra as temáticas abordadas na revista no período de 1979 à 1989. Nesta década foram publicados 275 artigos. Os temas estão na ordem dos mais abordados para os menos abordados. Conforme pode ser visto, nesta década o tema mais recorrente foi a Prática Profissional do Serviço Social. O tema envelhecimento não apareceu em nenhum dos artigos desta década.

\section{Quadro 1 - Temática abordada na Revista Serviço Social \& Sociedade no período de 1979 à 1989}

\begin{tabular}{|l|}
\multicolumn{1}{|c|}{ Temas abordados } \\
\hline Prática profissional do Serviço Social \\
\hline Saúde \\
\hline Participação social/ Participação popular \\
\hline Movimentos sociais populares/ movimento Operário/Gestão popular \\
\hline Política Social \\
\hline Formação profissional/ Currículo/Ensino/Estágio \\
\hline Trabalho comunitário/Desenvolvimento de Comunidade \\
\hline Pesquisa/ Produção do Conhecimento \\
\hline Família \\
\hline Criança/Menor \\
\hline Organização política dos assistentes sociais \\
\hline Educação popular/Organização popular/Cultura Popular \\
\hline Modelo funcional/ Teoria funcionalista/ Positivismo \\
\hline A profissão Serviço Social \\
\hline Política de Assistência Social \\
\hline Questão agrária/Agrícola/ Reforma agrária/Serviço Social Rural \\
\hline Ideologia/ Poder/ Hegemonia \\
\hline Estado de bem-estar social \\
\hline Serviço Social de empresa \\
\hline Pobreza/ Exclusão social \\
\hline História do Serviço Social \\
\hline Supervisão em Serviço Social \\
\hline Democracia \\
\hline
\end{tabular}


Metodologia do Serviço Social

Classes populares/ Classes subalternas

Trabalho Social/ Prática social

Trabalho

Estado

Movimento de mulheres/ Feminismo

Planejamento

Política Habitacional

Reconceituação do Serviço Social

Fonte: SILVA, 1999.

Na década de 1990 foram publicados 258 artigos, sendo a temática Trabalho a mais abordada nos artigos, conforme pode ser visto no quadro 2. Os temas estão na ordem dos mais abordados para os menos abordados. O tema envelhecimento apareceu em apenas três artigos.

\section{Quadro 2 - Temática abordada na Revista Serviço Social \& Sociedade na década de 1990}

\section{Temas abordados}

Trabalho/ Transformações no mundo do trabalho

Revolução informacional/ Nova ordem mundial/ Reestruturação industrial/

Transformações societárias/ Globalizaçãol Modernidadel Pós-modernidadel

Sociedade pós-industrial/ Neoliberalismo/ Crise do socialismo real

Política social/ Programas sociais

Política de assistência social

Prática profissional/ Práxis do Serviço Social/ Ação Profissional

Movimentos sociais/ Organização popular/ Participação popular

Direitos humanos/Direitos sociais/Cidadania

Formação profissional/ Ensino/ Estágio

Misérial Pobreza/ Exclusão social

Pesquisa/ Pesquisa em Serviço Social/ Pesquisa participante

Étical Ética profissional

Democracia

Família

Saúde

Renda mínima/ mínimos sociais

Mulher/ Feminismo

Descentralização/ Municipalização

Terceiro setor/ ONG

Profissão Serviço Social

Trabalho comunitário

Desenvolvimento de comunidade 
Conselhos populares

Educação

Criança/ Menor

Conceito de sociedade civil

Marxismo

Idoso/ Gerontologia

Universidade

Organização profissional

Estado

Política empresarial/ Empresa

Fonte: SILVA, 1999.

A revista começou a publicar números com uma temática específica, a partir da revista 50 em 1996. Conforme pode ser visto no quadro 3, os temas são bastante variados. A partir da de 2001, a revista passou a publicar um número especial, tendo sido publicado quatro números em que foram discutidos os seguintes temas:

- sócios-jurídicos;

- família e questão social;

- envelhecimento;

- formação e projeto ético-político.

Quadro 3 - Temáticas específicas abordadas nas revistas n 50 a n 93.

\begin{tabular}{|c|c|l|}
\hline Número da Revista & Ano de publicação & \multicolumn{1}{|c|}{ Temática } \\
\hline 50 & 1996 & O Serviço Social no século XXI \\
\hline 51 & 1996 & Identidade e formação profissional \\
\hline 52 & 1996 & Mundo do Trabalho \\
\hline 53 & 1997 & Política social e direitos humanos \\
\hline 54 & 1997 & $\begin{array}{l}\text { Descentralização, } \\
\text { participação }\end{array}$ \\
\hline 55 & 1997 & Mínimos sociais, exclusão social \\
\hline 56 & 1998 & Assistência social, sociedade civil \\
\hline 57 & 1998 & Temas contemporâneos \\
\hline 58 & 1998 & $\begin{array}{l}\text { Terceiro setor, movimento social } \\
\text { hoje }\end{array}$ \\
\hline 59 & 1999 & $\begin{array}{l}\text { Espaço público, } \\
\text { terceiro setor }\end{array}$ \\
\hline 60 & 1999 & $\begin{array}{l}\text { Crise e sistema de proteção social } \\
\text { 20 anos de Revista } \text { Serviço } \text { Social } \\
\text { \& Sociedade }\end{array}$ \\
\hline 61 & 1999 & $\begin{array}{l}\text { Processo de trabalho e Assistência } \\
\text { social }\end{array}$ \\
\hline 62 & 2000 & \multicolumn{2}{|c|}{} \\
\hline & &
\end{tabular}




\begin{tabular}{|c|c|c|}
\hline 63 & 2000 & $\begin{array}{l}\text { Enfrentamento da pobreza em } \\
\text { questão }\end{array}$ \\
\hline 64 & 2000 & Modernidade sombras e lutas \\
\hline 65 & 2001 & Seguridade Social e Cidadania \\
\hline 66 & 2001 & Fórum Social, Gestão de políticas \\
\hline 67 & 2001 & Especial; Temas sócio-jurídicos \\
\hline 68 & 2001 & Assistência e proteção social \\
\hline 69 & 2002 & Multifaces do trabalho \\
\hline 70 & 2002 & Violência - $1^{a}$ reimpressão \\
\hline 71 & 2002 & Famílias \\
\hline 72 & 2002 & $\begin{array}{l}\text { Cidade, Proteção e Controle Social } \\
-1^{a} \text { reimpressão }\end{array}$ \\
\hline 73 & 2003 & $\begin{array}{l}\text { Políticas Públicas e Sociedade } \\
\text { Civil }\end{array}$ \\
\hline 74 & 2003 & $\begin{array}{l}\text { Saúde, qualidade de vida } e \\
\text { Direitos. }\end{array}$ \\
\hline 75 & 2003 & Velhice e envelhecimento \\
\hline 76 & 2003 & Estado e regulação Social \\
\hline 77 & 2004 & $\begin{array}{l}\begin{array}{l}\text { Assistência Social políticas } \\
\text { direitos }\end{array} \\
\end{array}$ \\
\hline 78 & 2004 & Gestão Pública \\
\hline 79 & 2004 & $\begin{array}{l}\text { Serviço Social: formação e projeto } \\
\text { político }\end{array}$ \\
\hline 80 & 2004 & Política de Assistência Social \\
\hline 81 & 2005 & Temas em Debate \\
\hline 82 & 2005 & Trabalho e Saúde \\
\hline 83 & 2005 & Criança e Adolescente \\
\hline 84 & 2005 & $\begin{array}{l}\text { Reconceituação do Serviço Social: } \\
40 \text { Anos }\end{array}$ \\
\hline 85 & 2006 & $\begin{array}{l}\text { Ética execução de políticas } \\
\text { democracia participativa } 1^{\circ} \\
\text { Reimpressão }\end{array}$ \\
\hline 86 & 2006 & Espaço público e direitos sociais \\
\hline 87 & 2006 & Edição Especial - SUAS e SUS \\
\hline 88 & 2006 & $\begin{array}{l}\text { Espaço Público e Controle Social } \\
1^{\circ} \text { Reimpressão }\end{array}$ \\
\hline 89 & 2007 & $\begin{array}{l}\text { Ética Pública e Cultura de Direitos } \\
1^{\circ} \text { Reimpressão }\end{array}$ \\
\hline 90 & 2007 & Gestão pública \\
\hline 91 & 2007 & Projeto profissional e conjuntura \\
\hline 92 & 2007 & $\begin{array}{l}\text { Política social desafios para o } \\
\text { Serviço Social }\end{array}$ \\
\hline 93 & 2008 & Trabalho e trabalhadores \\
\hline
\end{tabular}

Fonte: CORTEZ EDITORA 


\section{Capítulo 3}

\section{Apresentação e análise dos dados}

O debate sobre envelhecimento é recente no contexto brasileiro. Dados do Instituto Brasileiro de Geografia Estatística (IBGE) mostram que a proporção de idosos na população brasileira é cada vez maior. Essa nova realidade demográfica cria novas demandas e desafios para a sociedade e o Estado. O Serviço Social no contato e intervenção na dinâmica social precisa compreender essa realidade e as novas expressões da questão social nesse contexto. Esse capítulo apresenta as análises dos dados a partir de duas referências: os autores e os artigos.

\subsection{Sobre os autores}

Foram consideradas informações de 23 autores (as) por meio de busca de currículo na Plataforma Lattes $^{2}$ do CNPq. Infelizmente, oito autoras não possuíam currículo cadastrado nesta Plataforma, o que dificultou a obtenção dos dados. Sendo possível identificar os dados apenas por meio do rodapé do artigo, com exceção, da autora Marta Regina Pastor Bruno, cujos dados são mais recentes (2003). Todos os autores encontrados são de nacionalidade brasileira.

Os artigos foram escritos em sua grande maioria por um único autor, com exceção de três artigos em co-autoria: Preparação para aposentadoria e os programas nesta área, que foi escrito por sete autoras; Crônica de viagem: um passeio por instituições asilares orientais, escrito por duas autoras e Resiliência: um enfoque para a promoção de saúde em idosos, também escrito por duas autoras.

Conforme pode ser visto no quadro 4, houve o predomínio de autoras do sexo feminino, 20 (sendo sete autoras de um único artigo), em relação ao sexo masculino, três autores.

2 Desenvolvida em 1999 pelo Conselho Nacional de Desenvolvimento Científico e Tecnológico (CNPq/MCT) para padronizar os currículos dos pesquisadores brasileiros e implementar um banco de dados público que, entre outros benefícios, possibilitasse a obtenção de um panorama da distribuição da pesquisa científica no Brasil. 
Quadro 4 - Autores dos artigos pesquisados na Revista Serviço Social \& Sociedade

\begin{tabular}{|c|c|}
\hline Artigo & Autor (a) \\
\hline Acreditando na velhice: novos caminhos & José Anísio da Silva \\
\hline $\begin{array}{l}\text { Preparação para aposentadoria e os programas } \\
\text { nesta área }\end{array}$ & $\begin{array}{l}\text { Beatriz Fortes Rey, } \\
\text { Jacqueline Rodrigues da } \\
\text { Silva, Marta Ponzi Pezzi, } \\
\text { Sandra Virgínia Tubino } \\
\text { Jorge, Sirlei Pompeo Costa, } \\
\text { Tânia Maria de Menezes, } \\
\text { Vera Regiana Capar Fritsch. }\end{array}$ \\
\hline $\begin{array}{l}\text { Gerontologia e interdisciplinaridade - fundamentos } \\
\text { epistemológicos }\end{array}$ & Jeanete Liasch Martins de Sá \\
\hline A longevidade da população: desafios e conquista & Renato Peixoto Veras \\
\hline $\begin{array}{l}\text { Envelhecimento populacional: uma conquista para } \\
\text { ser celebrada }\end{array}$ & $\begin{array}{l}\text { Marília Anselmo Viana da } \\
\text { Silva Berzins }\end{array}$ \\
\hline Modernidade e velhice & $\begin{array}{l}\text { Vera Lúcia Valsecchi de } \\
\text { Almeida }\end{array}$ \\
\hline Velhice: a identidade estigmatizada & Elisabeth F. Mercadante \\
\hline Cidadania não tem idade & Marta Regina Pastor Bruno \\
\hline Conselho do idoso como espaço público & $\begin{array}{l}\text { Sônia Mercedes Lenhard } \\
\text { Bredemeier }\end{array}$ \\
\hline $\begin{array}{l}\text { Cuidadores familiares de idosos: parceiros da } \\
\text { equipe de saúde }\end{array}$ & Ursula M. Karsch \\
\hline $\begin{array}{l}\text { O valor da atividade não remunerada realizada por } \\
\text { pessoas maiores de sessenta anos }\end{array}$ & Viviam C. Herrero Lemos \\
\hline Idosos: o medicamento intermediando as relações & Ruth Gelehter da Costa Lopes \\
\hline $\begin{array}{l}\text { Espaços internos e externos do corpo: } \\
\text { envelhecimento e autonomia }\end{array}$ & Pedro Paulo Monteiro \\
\hline $\begin{array}{l}\text { Crônica de viagem: um passeio por instituições } \\
\text { asilares orientais }\end{array}$ & $\begin{array}{l}\text { Maria Helena Villas Boas } \\
\text { Concone e } \\
\text { Chiou Ruey Ling }\end{array}$ \\
\hline $\begin{array}{l}\text { Resiliência: um enfoque para a promoção de saúde } \\
\text { em idosos }\end{array}$ & $\begin{array}{l}\text { Ana Valéria Rodrigues } \\
\text { Neide Cordeiro de Magalhães }\end{array}$ \\
\hline
\end{tabular}

\subsubsection{Formação acadêmica e pós-graduação}

A maioria dos autores dos artigos encontrados tiveram formação acadêmica em Serviço Social, 14 autores. Dentre os demais autores, dois tiveram formação na área de saúde: medicina e fisioterapia; três autoras cursaram ciências sociais; três autoras cursaram psicologia e uma autora cursou economia.

Não foi possível identificar se as autoras do artigo: Preparação para aposentadoria e os programas nesta área, possuem pós-graduação, pois elas não têm cadastro na Plataforma Lattes. Entre os demais autores dois possuem especialização, 
sendo uma dessas em Gerontologia; cinco autores são mestres em Gerontologia e nove possuem doutorado em diversas áreas, sendo três em Serviço Social. É importante ressaltar que dentre os que possuem doutorado, três autoras possuem especialização em Gerontologia. Diante desses dados, percebe-se que os autores estão de fato envolvidos com a temática envelhecimento e que a abordagem da temática concentra-se entre os autores que já apresentam um considerável percurso nesses estudos.

Quadro 5 - Formação acadêmica e pós-graduação dos autores dos artigos pesquisados na Revista Serviço Social \& Sociedade.

\begin{tabular}{|c|c|c|}
\hline Autor (a) & $\begin{array}{l}\text { Formação } \\
\text { acadêmica }\end{array}$ & Pós-graduação \\
\hline José Anísio da Silva & Serviço Social & Especialização em Gerontologia. \\
\hline Beatriz Fortes $^{3}$ & Serviço Social & Não informada \\
\hline $\begin{array}{l}\text { Jacqueline } \text { Rodrigues } \mathrm{da} \\
\text { Silva }\end{array}$ & Serviço Social & Não informada \\
\hline Marta Ponzi Pezzi & Serviço Social & Não informada \\
\hline $\begin{array}{lll}\text { Sandra } & \text { Virginia } & \text { Tubino } \\
\text { Jorge } & & \\
\end{array}$ & Serviço Social & Não informada \\
\hline Sirlei Pompeo Costa & Serviço Social & Não informada \\
\hline Tânia Maria de Menezes & Serviço Social & Não informada \\
\hline Vera Regiana Capra Fritsch & Serviço Social & Não informada \\
\hline $\begin{array}{l}\text { Jeanete Liasch Martins de } \\
\text { Sá }\end{array}$ & Serviço Social & $\begin{array}{l}\text { Doutorado em Serviço Social } \\
\text { especialização em Gerontologia. }\end{array}$ \\
\hline Renato Peixoto Veras & Medicina & $\begin{array}{l}\text { Doutorado em Epidemiologia do } \\
\text { Envelhecimento. }\end{array}$ \\
\hline $\begin{array}{l}\text { Marília Anselmo Viana da } \\
\text { Silva Berzins }\end{array}$ & Serviço Social & Mestrado em Gerontologia \\
\hline $\begin{array}{l}\text { Vera Lúcia Valsecchi de } \\
\text { Almeida }\end{array}$ & Ciências Sociais & Doutorado em Ciências Sociais. \\
\hline Elisabeth F. Mercadante & Ciências Sociais & Doutorado em Ciências Sociais. \\
\hline Marta Regina Pastor Bruno & Serviço Social & Mestrado em Gerontologia \\
\hline $\begin{array}{l}\text { Sônia Mercedes Lenhard } \\
\text { Bredemeier }\end{array}$ & Serviço Social & $\begin{array}{l}\text { Doutorado em Serviço Social } \\
\text { especialização em Gerontologia. }\end{array}$ \\
\hline Ursula M. Karsch & Serviço Social & Doutorado em Serviço Social \\
\hline Viviam C. Herrero Lemos & Economia & Mestrado em Gerontologia \\
\hline $\begin{array}{l}\text { Ruth Gelehter da Costa } \\
\text { Lopes }\end{array}$ & Psicologia & $\begin{array}{l}\text { Doutorado em Saúde Pública } \\
\text { especialização em Gerontologia. }\end{array}$ \\
\hline Pedro Paulo Monteiro & Fisioterapia & Mestrado Gerontologia \\
\hline Maria Helena Villas Boas & Ciências Sociais & Doutorado em Antropologia \\
\hline
\end{tabular}

3 As autoras que não têm a coluna pós-graduação informada não possuem currículo lattes. A informação referente à formação acadêmica foi encontrada no rodapé do artigo Preparação para a aposentadoria e os programas nesta área. 


\begin{tabular}{|l|l|ll|} 
Concone & & \\
\hline Chiou Ruey Ling & Psicologia & Mestrado em Gerontologia & \\
\hline Ana Valéria Rodrigues & Serviço Social & $\begin{array}{l}\text { Especialização } \\
\text { desenvolvimento humano }\end{array}$ \\
\hline $\begin{array}{l}\text { Neide Cordeiro de } \\
\text { Magalhães }\end{array}$ & Psicologia & Doutorado em humanidades & \\
\hline
\end{tabular}

\subsubsection{Vínculo institucional e região dos autores}

De acordo com os dados obtidos, constados no quadro 6, a maioria dos autores apresenta vínculo com uma universidade confessional católica (setor privado) e estão situados na região Sudeste. É importante ressaltar que os autores dos artigos encontrados situam-se ou na região Sudeste ou na Região Sul. Não foi possível encontrar o vínculo das autoras do artigo: Preparação para aposentadoria e os programas nesta área. No entanto, no rodapé do artigo há uma nota que as situa como sendo integrantes do Conselho do Idoso do Rio Grande do Sul em 1994.

Nas regiões Sul e Sudeste é onde se encontram os estados de maior percentual de idosos sobre a população total: Rio de Janeiro, 10,7\% e Rio Grande do Sul, 10,4\%. Entretanto, há estados na região Norte e Nordeste com elevado percentual de idosos como, por exemplo, a Paraíba, 10,1\% e o Rio Grande do Norte, 9,0\% (IBGE, 2000), mas, dentre os autores encontrados, nenhum possui vínculo institucional nestas regiões.

A distribuição regional das autoras coincidiu parcialmente com um estudo do perfil da pós-graduação em Serviço Social no Brasil realizado por Yazbeck \& Silva (2005), em que a maior incidência de cursos de pós-graduação nas regiões é respectivamente da região Sudeste, seguida pelas regiões Nordeste, Sul e Centro-Oeste e Norte. Como pode ser visto pelos dados obtidos, nenhum dos autores apresenta vínculo institucional na Região Nordeste.

Quadro 6 - Vínculo institucional e região dos autores dos artigos pesquisados na Revista Serviço Social \& Sociedade.

\begin{tabular}{|l|l|l|}
\hline \multicolumn{1}{|c|}{ Autor (a) } & Vínculo Institucional & \multicolumn{1}{c|}{ Região / Estado } \\
\hline José Anísio da Silva & Prefeitura de Juiz de Fora & Sudeste - MG \\
\hline Beatriz Fortes & Não informado & Não informada \\
\hline Jacqueline Rodrigues da Silva & Não informado & Não informada \\
\hline Marta Ponzi Pezzi & Não informado & Não informada \\
\hline Sandra Virginia Tubino Jorge & Não informado & Não informada \\
\hline Sirlei Pompeo Costa & Não informado & Não informada \\
\hline
\end{tabular}




\begin{tabular}{|l|l|l|} 
Tânia Maria de Menezes & Não informado & Não informada \\
\hline Vera Regiana Capra Fritsch & Não informado & Não informada \\
\hline Jeanete Liasch Martins de Sá & $\begin{array}{l}\text { Pontifícia Universidade } \\
\text { Católica }\end{array}$ & Sudeste - SP \\
\hline Renato Peixoto Veras & $\begin{array}{l}\text { Universidade do Estado do Rio } \\
\text { de Janeiro }\end{array}$ & Sudeste - RJ \\
\hline $\begin{array}{l}\text { Marília Anselmo Viana da } \\
\text { Silva Berzins }\end{array}$ & $\begin{array}{l}\text { Pontifícia Universidade } \\
\text { Católica }\end{array}$ & Sudeste - SP \\
\hline $\begin{array}{l}\text { Vera Lúcia Valsecchi de } \\
\text { Almeida }\end{array}$ & $\begin{array}{l}\text { Pontifícia Universidade } \\
\text { Católica }\end{array}$ & Sudeste - SP \\
\hline Elisabeth F. Mercadante & $\begin{array}{l}\text { Pontifícia Universidade } \\
\text { Católica }\end{array}$ & Sudeste - SP \\
\hline Marta Regina Pastor Bruno & Não informado & Não informada \\
\hline $\begin{array}{l}\text { Sônia Mercedes Lenhard } \\
\text { Bredemeier }\end{array}$ & $\begin{array}{l}\text { Universidade do Vale do Rio } \\
\text { dos Sinos }\end{array}$ & Sul - RS \\
\hline Ursula M. Karsch & $\begin{array}{l}\text { Pontifícia Universidade } \\
\text { Católica }\end{array}$ & Sudeste - SP \\
\hline Viviam C. Herrero Lemos & Rhodia S.A & Não informada \\
\hline Ruth Gelehter da Costa Lopes & $\begin{array}{l}\text { Pontifícia Universidade } \\
\text { Católica }\end{array}$ & Sudeste - SP \\
\hline Pedro Paulo Monteiro & $\begin{array}{l}\text { Universidade Fundação } \\
\text { Oswaldo Aranha }\end{array}$ & Sudeste - RJ \\
\hline $\begin{array}{l}\text { Maria Helena Villas Boas } \\
\text { Concone }\end{array}$ & $\begin{array}{l}\text { Pontifícia Universidade } \\
\text { Católica }\end{array}$ & Sudeste - SP \\
\hline Chiou Ruey Ling & Universidade Santa Cecília & Sudeste - SP \\
\hline Ana Valéria Rodrigues & Faculdade Interativa COC & Sudeste - MG \\
\hline Neide Cordeiro de Magalhães & $\begin{array}{l}\text { Universidade Federal de Juiz } \\
\text { de Fora }\end{array}$ & Sudeste - MG \\
\hline
\end{tabular}

\subsection{Sobre os artigos}

\subsubsection{Artigos, número da revista e ano de publicação}

Foram encontrados e analisados 15 artigos sobre envelhecimento, que possuem em média 15 páginas, onde o menor artigo tem nove e o maior, 24 páginas ${ }^{4}$. Apenas 12 artigos possuem resumo, uma vez que, essa norma de publicação foi estabelecida na revista somente a partir de 2002. O quadro abaixo relaciona todos os artigos da revista que tratam do tema envelhecimento e o número da revista publicada com o ano de publicação.

\section{Quadro 7 - Artigos pesquisados com número da Revista Serviço Social \& Sociedade e ano de publicação.}

A revista estabelece o limite máximo de 30 laudas de 25 linhas de 70 toques. 


\begin{tabular}{|c|c|c|}
\hline Artigo & $\begin{array}{c}\mathbf{N}^{\circ} \text { da } \\
\text { Revista }\end{array}$ & $\begin{array}{c}\text { Ano de } \\
\text { publicação }\end{array}$ \\
\hline Acreditando na velhice: novos caminhos & 37 & 1991 \\
\hline Preparação para aposentadoria e os programas nesta área & 52 & 1996 \\
\hline $\begin{array}{l}\text { Gerontologia e interdisciplinaridade }- \text { fundamentos } \\
\text { epistemológicos }\end{array}$ & 58 & 1998 \\
\hline A longevidade da população: desafios e conquista & 75 & 2003 \\
\hline $\begin{array}{l}\text { Envelhecimento populacional: uma conquista para ser } \\
\text { celebrada }\end{array}$ & 75 & 2003 \\
\hline Modernidade e velhice & 75 & 2003 \\
\hline Velhice: a identidade estigmatizada & 75 & 2003 \\
\hline Cidadania não tem idade & 75 & 2003 \\
\hline Conselho do idoso como espaço público & 75 & 2003 \\
\hline $\begin{array}{l}\text { Cuidadores familiares de idosos: parceiros da equipe de } \\
\text { saúde }\end{array}$ & 75 & 2003 \\
\hline $\begin{array}{l}\text { O valor da atividade não remunerada realizada por pessoas } \\
\text { maiores de sessenta anos }\end{array}$ & 75 & 2003 \\
\hline Idosos: o medicamento intermediando as relações & 75 & 2003 \\
\hline $\begin{array}{l}\text { Espaços internos e externos do corpo: envelhecimento e } \\
\text { autonomia }\end{array}$ & 75 & 2003 \\
\hline $\begin{array}{l}\text { Crônica de viagem: um passeio por instituições asilares } \\
\text { orientais }\end{array}$ & 75 & 2003 \\
\hline Resiliência: um enfoque para a promoção de saúde em idosos & 93 & 2008 \\
\hline
\end{tabular}

Do total analisado, 11 artigos foram publicados na Revista Serviço Social \& Sociedade especial $n^{\circ} 75$ em 2003. Já os demais artigos foram publicados na Revista Serviço Social \& Sociedade no 37 em 1991, nº 52 em 1996, nº 58 em 1998 e nº 93 em 2008. Analisando a data de publicação dos artigos percebe-se que não há regularidade na mesma. Sendo que o maior número de artigos foi publicado em outubro de 2003, mesmo mês e ano da criação do Estatuto do Idoso, o que permite inferir que esse número especial da Revista Serviço Social \& Sociedade foi fruto dos inúmeros debates fomentados para criação deste Estatuto. É importante ressaltar, que somente após cinco anos da publicação do número especial Velhice e envelhecimento, é que houve uma nova publicação na revista de um artigo sobre a temática.

\subsubsection{Tema das revistas}

A Revista Serviço Social \& Sociedade somente passou a publicar artigos por área temática a partir da revista $\mathrm{n}^{\circ} 50 \mathrm{em} 1996$, por isso, o artigo publicado na revista $\mathrm{n}^{\circ}$ 37 não faz parte de uma revista temática. A revista $\mathrm{n}^{\circ} 52$ na qual foi publicado o artigo: Preparação para aposentadoria e os programas nesta área, teve como tema Mundo do 
Trabalho. A revista $\mathrm{n}^{\circ}$ 58, na qual foi publicado o artigo: Gerontologia $e$ interdisciplinaridade - fundamentos epistemológicos teve como tema Terceiro Setor e Movimentos Sociais hoje. A revista $\mathrm{n}^{\circ}$ 93, na qual foi publicado o artigo: Resiliência: um enfoque para a promoção de saúde em idosos, a temática foi Trabalho e Trabalhadores. Já os demais artigos foram publicados na revista especial com o tema Velhice e Envelhecimento.

Quadro 8 - Temas dos números das Revistas Serviço Social \& Sociedade com artigos publicados sobre envelhecimento.

\begin{tabular}{|l|l|}
\hline \multicolumn{1}{|c|}{$\mathbf{N}^{\mathbf{0}}$ da Revista } & \multicolumn{1}{c|}{ Tema } \\
\hline $\mathrm{N}^{\mathbf{o}} 37$ & Não contém \\
\hline $\mathrm{N}^{\mathbf{o}} 52$ & Mundo do Trabalho \\
\hline $\mathrm{N}^{\mathbf{0}} 58$ & Terceiro Setor e Movimentos Sociais hoje \\
\hline $\mathrm{N}^{\mathrm{o}} 75$ & Velhice e Envelhecimento \\
\hline $\mathrm{N}^{\circ} 93$ & Trabalho e Trabalhadores \\
\hline
\end{tabular}

\subsubsection{Palavras - chave}

Somente a partir de 2003, os artigos publicados nesta revista começaram a apresentar palavras-chave. Logo, os artigos: Acreditando na velhice: novos caminhos; Preparação para aposentadoria e os programas nesta área e Gerontologia e interdisciplinaridade - fundamentos epistemológicos, publicados respectivamente em 1991, 1996 e 1998, não contêm palavras-chave. Já os demais artigos contam com as palavras-chave mostradas no Quadro 9.

\section{Quadro 9 - Palavras-chave dos artigos pesquisados na Revista Serviço Social \& Sociedade.}

\begin{tabular}{|l|l|}
\hline \multicolumn{1}{|c|}{ Artigo $^{5}$} & \multicolumn{1}{|c|}{ Palavras - chave } \\
\hline $\begin{array}{l}\text { Acreditando na velhice: novos caminhos } \\
\text { Preparação para aposentadoria e os } \\
\text { programas nesta área }\end{array}$ & Não contém \\
\hline $\begin{array}{l}\text { Gerontologia e interdisciplinaridade - } \\
\text { fundamentos epistemológicos }\end{array}$ & Não contém \\
\hline $\begin{array}{l}\text { A longevidade da população: desafios e } \\
\text { conquista }\end{array}$ & $\begin{array}{l}\text { Longevidade, transição demográfica, } \\
\text { saúde do idoso }\end{array}$ \\
\hline $\begin{array}{l}\text { Envelhecimento populacional: } \quad \text { uma } \\
\text { Envelhecimento, dados estatísticos, Brasil }\end{array}$ \\
\hline
\end{tabular}

$5 \quad$ O resumo dos artigos das revistas $n^{\circ} 75$ e 93 estão em anexo. Os demais não apresentam resumo. 


\begin{tabular}{|c|c|}
\hline Modernidade e velhice & Velhice, modernidade, imagens visuais \\
\hline Velhice: a identidade estigmatizada & $\begin{array}{l}\text { Velho, identidade, corpo, trabalho e } \\
\text { família }\end{array}$ \\
\hline Cidadania não tem idade & Cidadania, velhice \\
\hline Conselho do idoso como espaço público & $\begin{array}{l}\begin{array}{l}\text { Democracia, } \\
\text { descentralização, espaço } \\
\text { conselhos }\end{array} \\
\end{array}$ \\
\hline $\begin{array}{l}\text { Cuidadores familiares de idosos: } \\
\text { parceiros da equipe de saúde }\end{array}$ & $\begin{array}{l}\begin{array}{l}\text { Idosos com dependência, } \\
\text { familiares, cuidadores } \\
\text { envelhecimento. }\end{array} \\
\text { domiciliar, }\end{array}$ \\
\hline $\begin{array}{l}O \text { valor da atividade não remunerada } \\
\text { realizada por pessoas maiores de } \\
\text { sessenta anos }\end{array}$ & $\begin{array}{l}\text { Atividade, envelhecimento, valor } \\
\text { econômico }\end{array}$ \\
\hline $\begin{array}{l}\text { Idosos: o medicamento intermediando as } \\
\text { relações }\end{array}$ & $\begin{array}{l}\text { Saúde na velhice, automedicação, relação } \\
\text { profissional e idoso. }\end{array}$ \\
\hline $\begin{array}{l}\text { Espaços internos e externos do corpo: } \\
\text { envelhecimento e autonomia }\end{array}$ & $\begin{array}{l}\text { corpo, espaço de moradia, tempo, } \\
\text { envelhecimento, autonomia }\end{array}$ \\
\hline $\begin{array}{l}\text { Crônica de viagem: um passeio por } \\
\text { instituiçõos asilares orientais }\end{array}$ & $\begin{array}{l}\text { Instituição asilar, envelhecimento, } \\
\text { cultura. }\end{array}$ \\
\hline $\begin{array}{l}\text { Resiliência: um enfoque para a } \\
\text { promoção de saúde em idosos }\end{array}$ & $\begin{array}{l}\text { Políticas públicas; resiliência, } \\
\text { envelhecimento bem-sucedido }\end{array}$ \\
\hline
\end{tabular}

É importante ressaltar, que houve apenas repetição das palavras-chave: corpo, envelhecimento, idosos, saúde e velhice, conforme apresentado no Gráfico 1.

\section{Gráfico 1 - Palavras-chave com maior freqüência nos artigos pesquisados na Revista Serviço Social \& Sociedade.}

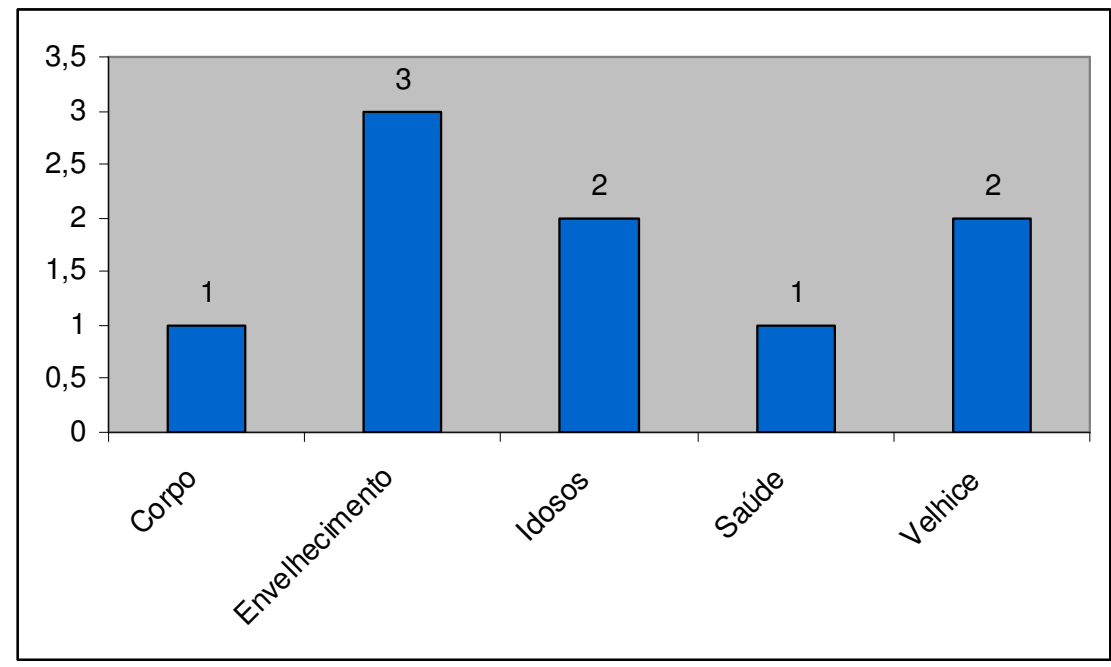

\subsubsection{Metodologia utilizada nos artigos}


Alguns autores não mencionaram a metodologia utilizada em seu estudo. Dentre os 15 artigos analisados, houve o predomínio do uso de pesquisa teórica. Esta metodologia foi utilizada em nove artigos. Entre os seis artigos, em que foi utilizada a pesquisa empírica, os autores fizeram uso das técnicas de entrevista, estudo de caso e análise documental, conforme o quadro abaixo.

Quadro 10 - Metodologia utilizada nos artigos pesquisados na Revista Serviço Social \& Sociedade.

\begin{tabular}{|l|l|}
\hline \multicolumn{1}{|c|}{ Artigo } & \multicolumn{1}{|c|}{ Metodologia utilizada } \\
\hline Acreditando na velhice: novos caminhos & $\begin{array}{l}\text { Pesquisa empírica - estudo de } \\
\text { caso }\end{array}$ \\
\hline $\begin{array}{l}\text { Preparação para aposentadoria e os programas } \\
\text { nesta área }\end{array}$ & $\begin{array}{l}\text { Elaborado por assistentes } \\
\text { sociais do Conselho Estadual } \\
\text { do Idoso do RS, no I Seminário } \\
\text { sobre Preparação para } \\
\text { Aposentadoria. }\end{array}$ \\
\hline $\begin{array}{l}\text { Gerontologia e interdisciplinaridade - } \\
\text { fundamentos epistemológicos }\end{array}$ & Pesquisa teórica \\
\hline A longevidade da população: desafios e conquista & Pesquisa teórica \\
\hline $\begin{array}{l}\text { Envelhecimento populacional: uma conquista para } \\
\text { ser celebrada }\end{array}$ & Pesquisa teórica \\
\hline Modernidade e velhice & Pesquisa teórica \\
\hline $\begin{array}{l}\text { Velhice: a identidade estigmatizada } \\
\text { Cidadania não tem idade }\end{array}$ & Pesquisa empírica, entrevistas \\
\hline $\begin{array}{l}\text { Conselho do idoso como espaço público } \\
\text { Pesquisa teórica }\end{array}$ \\
\hline $\begin{array}{l}\text { Cuidadores familiares de idosos: parceiros da } \\
\text { equipe de saúde }\end{array}$ & $\begin{array}{l}\text { Pesquisa empírica, análise } \\
\text { documental e (atas do conselho) }\end{array}$ \\
\hline $\begin{array}{l}\text { O valor da atividade não remunerada realizada } \\
\text { por pessoas maiores de sessenta anos }\end{array}$ & Pesquisa empírica, entrevistas \\
\hline Idosos: o medicamento intermediando as relações & Pesquisa teórica \\
\hline $\begin{array}{l}\text { Espaços internos externos do corpo: } \\
\text { envelhecimento e autonomia }\end{array}$ & Pesquisa teórica \\
\hline $\begin{array}{l}\text { Crônica de viagem: um passeio por instituições } \\
\text { asilares orientais }\end{array}$ & $\begin{array}{l}\text { Pesquisa empírica, estudo de } \\
\text { caso }\end{array}$ \\
\hline $\begin{array}{l}\text { Resiliência: um enfoque para a promoção de saúde } \\
\text { em idosos }\end{array}$ & Pesquisa teórica \\
\hline
\end{tabular}

\subsubsection{Artigos publicados por assistentes sociais:}

Dentre os 15 artigos encontrados na revista, oito foram produzidos por assistentes sociais. Não houve repetição de nenhum assunto nos artigos. 
Percebe-se que em todos os artigos os idosos foram tratados como sujeito de direitos, foram vistos em sua integralidade e que está presente uma preocupação com a valorização desse segmento e com a sua digna inserção na sociedade.

No entanto, há uma carência nesses artigos sobre a inserção e atuação do Serviço Social com essa temática, tendo em vista que os autores focaram os seus artigos nos aspectos mais gerais. Além disso, percebe-se a necessidade da análise da questão do idoso após a promulgação de seu Estatuto. É evidente que apenas um dos 15 artigos foi publicado após a aprovação do Estatuto, no entanto, já se passaram quase cinco anos e ainda não houve nenhuma publicação na revista sobre essa questão.

Os principais assuntos abordados dos artigos foram: centro de convivência, cidadania, Conselhos, cuidadores, envelhecimento populacional, gerontologia e interdisciplinaridade, preparação para aposentadoria, resiliências e políticas públicas.

$\mathrm{O}$ primeiro deles, Acreditando na velhice: novos caminhos foi publicado em 1991. Havia decorrido cerca de 3 anos da promulgação da Constituição Federal. Tratase de um relato da experiência profissional do autor em um Centro de convivência do Idoso. Esse centro se constituía num espaço de encontro de idosos, onde eram difundidos os seus direitos sociais e de saúde, bem como a tentativa de integração com a família. Esse Centro teve sua criação amparada na Lei de Amparo à Velhice de 1974. O autor descreve o seu funcionamento e pontua algumas proposições para melhoria de vida da população idosa. Convém ressaltar que a seção em que o autor faz estas proposições é intitulada Sonho de modificar e o subitem Que bom seria. Isso mostra a precariedade das leis para os idosos existentes naquela época e a lógica perversa da sociedade onde as pessoas precisam sonhar com uma vida mais digna, sendo que isso já deveria ser algo inerente à existência humana. Uma das proposições do autor se refere ao uso da mídia para transmitir uma imagem mais real e justa dos idosos visando à diminuição dos preconceitos e tabus contra esse grupo. No entanto, percebe-se que apesar de terem passados aproximadamente 17 anos desta proposição, a mídia ainda continua contribuindo para estigmatização dos idosos com a difusão de uma imagem generalizada da velhice associando-a a fragilidade, dependência, egoísmo, inatividade, "rabugice".

O artigo Preparação para a aposentadoria e os programas nesta área, publicado na revista em 1996, foi extraído do Manual de implantação de Programas de 
Preparação para Aposentadoria, lançado pelo Conselho do Idoso do Rio Grande do Sul em 1994. No artigo é explicado o que são os programas para a aposentadoria; o seu objetivo; quais os recursos humanos e materiais para sua implantação; como fazer a implantação do Programa e o que deve conter no seu conteúdo programático: aspectos jurídicos-previdênciários; aspectos de seguridade social da empresa; aspectos econômico-financeiros; aspectos de saúde, aspectos psicológicos; aspectos sociais e aspectos de lazer.

No artigo Gerontologia e interdisciplinaridade - fundamentos epistemológicos, publicado em 1998, a interdisciplinaridade é apresentada como sendo algo constitutivo da Gerontologia. A autora trata da natureza interventiva da gerontologia e do seu processo de estruturação científica.

$\mathrm{O}$ artigo Envelhecimento populacional: uma conquista celebrada, publicado em 2003, apresenta um panorama geral do fenômeno do envelhecimento mundial e brasileiro por meio de dados estatísticos. A autora aborda as questões da feminização do envelhecimento, da renda e consumo, da escolaridade e dos idosos morando sozinhos.

No artigo Cidadania não tem idade, publicado em 2003, é trabalhada a educação para cidadania. A autora menciona neste artigo que o Estatuto do Idoso havia sido aprovado na Câmara dos Deputados e estava sendo enviado para o Senado. Ela fala sobre o distanciamento entre a legislação e a realidade dos idosos brasileiros e da necessidade de fomentar o debate e estimular a mobilização permanente da sociedade para que esta situação se modifique. Nesse artigo a autora apresenta o relato de um caso real de uma aluna de uma Universidade Aberta a Terceira Idade como um exercício de cidadania.

O artigo Conselho do Idoso como espaço público, publicado em 2003, tem como referencial teórico as posições de Hannah Arendt. A autora coloca a participação junto aos conselhos como uma nova demanda para os assistentes sociais. Nesse artigo é analisado o conteúdo das atas registradas, num período de 10 anos, de um Conselho do Idoso no Rio Grande do Sul.

No artigo Cuidadores familiares de Idosos: parceiros da equipe de saúde, publicado em 2003, está presente a preocupação com o bem-estar do cuidador do idoso. Enfatiza que há uma ausência de parceria entre esse e a equipe de saúde, sendo que essa parceria é muito importante para a promoção do bem-estar do idoso. 
$\mathrm{O}$ artigo Resiliência ${ }^{6}$ : um enfoque para promoção de saúde em idosos foi escrito por uma assistente social e uma psicóloga e foi publicado em 2008, quase cinco anos após a aprovação do Estatuto. Na primeira parte do artigo é apresentado o desenvolvimento histórico de resiliência. Na segunda parte a resiliência é analisada como um processo de reabilitação nas políticas públicas. Nesta parte elas destacam os principais marcos referentes às políticas públicas voltadas para os idosos. Há menção às Universidades Abertas à Terceira Idade, que inclusive esteve presente em outros artigos estudados nessa pesquisa.

\subsubsection{Saúde, previdência e assistência social}

A inserção deste item na pesquisa ocorreu devido a grande atuação dos assistentes sociais nestas áreas. Dentre elas, houve o predomínio nos artigos da área saúde, sendo esta abordada, principalmente, no aspecto biomédico e não enquanto política social. Esse predomínio da área saúde pode ser devido ao envelhecimento estar associado a uma maior fragilidade física. As outras duas áreas apareceram nos artigos de forma bastante pulverizada e incipiente. Percebe-se que há uma grande carência na produção de conhecimento científico que relacione o tema envelhecimento com a Seguridade Social, principalmente no Serviço Social.

\subsubsection{Envelhecimento e Revista Serviço Social \& Sociedade}

Os artigos publicados na Revista Serviço Social \& Sociedade abordaram os mais variados assuntos relacionados com a temática, dentre eles: a imprecisão do termo velhice; a solidão das mulheres idosas; a relação familiar do idoso; o valor do trabalho não remunerado do idoso e a imagem do idoso.

Alguns autores fizeram comparações do fenômeno entre diferentes países, outros mostraram o fenômeno por meio de dados estatísticos. Apesar da maioria dos artigos encontrados terem sido publicadas no momento em que o Estatuto do Idoso estava sendo aprovado, somente os artigos: Cidadania não tem idade e Resiliência: um enfoque para a promoção de saúde em idosos fizeram menção ao Estatuto.

É importante ressaltar que as Universidades Abertas à Terceira Idade foram mencionadas em vários dos artigos analisados. Percebe-se que alguns dos autores atuam

6 Trata-se da capacidade das pessoas saírem fortalecidas de situações adversas e que as deixam vulnerabilizadas. 
nessas Universidades. Elas foram apresentadas como espaços de convivência entre gerações, que centram suas atividades, preferencialmente, em programas de educação permanente, tornando-se um espaço em que os idosos podem relacionar-se, utilizar criativamente seu tempo, estudar e atualizar-se em cursos regulares ou organizados de acordo com seu perfil.

Apesar de a revista ter publicado um número especial sobre a velhice, às publicações sobre o tema ocorreram esporadicamente. Não houve uma regularidade. A maioria dos artigos se concentram nesse número especial que foi lançado na época que culminava a aprovação do Estatuto do Idoso, provavelmente porque havia um efervescente debate nesse contexto.

A questão do envelhecimento esteve sempre presente na sociedade ganhando maior visibilidade a partir de 1960 devido ao fenômeno do crescimento do envelhecimento populacional. No entanto, esta questão apareceu na revista apenas em 1991, após 12 anos de sua criação. Durante esse período não havia sido publicado nenhum artigo sobre o tema. Depois do primeiro artigo publicado, apenas houve uma nova publicação em 1996 e as próximas foram em 1998 e 2003. Devido à descontinuidade não é possível ver como o Estatuto do Idoso estava sendo concebido na produção do conhecimento no Serviço Social. Passaram-se quase cinco anos da aprovação do Estatuto e outro artigo sobre o tema envelhecimento só veio a ser publicado recentemente, em março deste ano (revista $n^{\circ}$. 93). Mesmo com a aprovação do Estatuto não houve um fomento da discussão sobre o tema no Serviço Social.

Diante disso, pode-se afirmar baseando-se nas publicações da Revista Serviço Social \& Sociedade que o campo do envelhecimento ainda se faz incipiente na produção do conhecimento do Serviço Social. Há uma necessidade de que este campo seja estabelecido no Serviço Social fazendo com que o diálogo se torne permanente a fim de que o Serviço Social, como uma área do saber, possa também contribuir para a melhoria da realidade da população idosa. 


\section{Considerações finais}

O tema envelhecimento, nos últimos anos, tem despertado uma maior atenção da sociedade. Isto pode ser constatado pela crescente quantidade de trabalhos (artigos, monografias, dissertações e teses) produzidos acerca deste tema. $\mathrm{O}$ envelhecimento da população mundial que por muito tempo foi relegado à esfera familiar tornou-se uma questão pública com atuações específicas do Estado por meio de políticas públicas e sociais.

O crescimento dos idosos em todo o mundo é um fenômeno único na história humana. Nunca havíamos chegado a idades tão avançadas e em tão grande número. $\mathrm{O}$ Brasil em breve se tornará a sexta população de idosos no mundo, devido ao grande avanço tecnológico, intensificado na segunda metade do século XX, facilitando as conquistas da medicina, da saúde e da genética.

A presente monografia foi desenvolvida com o intuito de saber como o tema envelhecimento se expressa na produção do conhecimento do Serviço Social. Após a análise dos artigos que tratam sobre este tema na Revista Serviço Social \& Sociedade, pode-se afirmar que a publicação sobre envelhecimento no Serviço Social é eminentemente produzida por autores do sexo feminino, com vínculo em universidade confessional católica e encontra-se concentrada na região sudeste.

Destaca-se que dos 719 projetos de pesquisa no âmbito dos programas de PósGraduação do Serviço Social, no período de 2001 a 2003, apenas dois projetos foram na área de transição demográfica e processo de envelhecimento. Na Revista Serviço Social \& Sociedade, a publicação em envelhecimento representa um número muito baixo. De um universo de mais de 550 artigos, apenas 15 referiam-se à temática envelhecimento, o que representa aproximadamente $2,73 \%$ de todos os artigos publicados.

Todas essas evidências convergem para a confirmação da hipótese de que há uma lacuna do campo envelhecimento na produção do conhecimento do Serviço Social. Os resultados apontam que há uma descontinuidade nas publicações sobre este tema. $\mathrm{O}$ primeiro artigo só foi publicado em 1991 e os demais em 1996, 1998, 2003 e 2008. As produções estiveram concentradas no ano de promulgação do Estatuto do Idoso e somente após aproximadamente cinco anos da aprovação desse foi publicado outro artigo sobre o tema. 
Percebe-se que embora haja a conquista de inúmeros direitos pelos idosos no Brasil, particularmente após a promulgação do Estatuto do Idoso, há a necessidade de pesquisas sobre o impacto que o Estatuto tem causado na vida dos idosos brasileiros. Esta lacuna deve ser repensada e preenchida, uma vez que como expressão da questão social, o envelhecimento populacional constitui uma demanda importante para os assistentes sociais e requer maior atenção e estudo por parte dos pesquisadores.

A abertura de editais de pesquisa sobre o envelhecimento pelo $\mathrm{CNPq}$ poderia contribuir para incentivar e fomentar a criação de linhas de pesquisa sobre este tema. Há muito que se pesquisar nesta área, dentre elas: a educação dos idosos, pelo fato do grande percentual de analfabetos nesse grupo etário; o trabalho, uma vez que, hoje, a população idosa mantém sua capacidade funcional por muito tempo além da aposentadoria; o HIV/AIDS nessa população, por não haver uma política de saúde voltada para esse aspecto da saúde do idoso, bem como a questão da sexualidade que se torna um tabu ainda maior quando se refere aos idosos; e a questão da convivência familiar e comunitária, bem como, o espaço que o idoso ocupa na sociedade, dentre outras. Não se pode esquecer que as pesquisas subsidiam as ações governamentais na criação das políticas públicas. Daí a importância do incentivo à pesquisa.

Por fim, faz-se importante ressaltar, que embora tenha sido analisado um único periódico do Serviço Social, a análise de outros periódicos da área, constitui um objeto importante para futuras pesquisas sobre o tema envelhecimento. 


\section{Referências bibliográficas}

BACELAR, Rute. O Desejo não tem idade: A sexualidade da mulher idosa. Recife: FASA, 2002.

BERZINS, Marília Anselmo Viana da Silva. Envelhecimento populacional: uma conquista para ser celebrada. In: Revista Serviço Social \& Sociedade, nº 75 . Ano XXIV. São Paulo: Cortez, 19-34, 2003.

BRASIL. Constituição da República Federativa do Brasil. Brasília: Senado Federal, 1988.

. Estatuto do idoso. Lei nº. 10.741, de 01 de outubro de 2003.

Lei Orgânica da Assistência Social. Lei n. 8742, de 7 de dezembro de 1993.

Política Nacional do Idoso. Lei nº 8.842, de 04 de janeiro de 1994.

CAMARANO, Ana Amélia. Envelhecimento da população brasileira: uma contribuição demográfica. Rio de Janeiro: Instituto de Pesquisa Econômica Aplicada, 2002.

CAMARANO, Ana Amélia; PASINATO, Maria Teresa. O envelhecimento populacional na agenda das políticas públicas. In: CAMARANO, A. A. (Org.). Os novos idosos brasileiros: muito além dos 60? Rio de Janeiro: Ipea, 2004.

CARVALHO, Denise Bomtempo Birche de; SILVA, Maria Ozanira (Orgs.). Serviço Social, Pós-graduação e produção de conhecimento no Brasil. São Paulo: Cortez, 2005.

COSTA, Neidil Espinola da; MENDONÇA, Jurilza Maria; ABIGALIL, Albamaria. Políticas de assistência ao idoso: a construção da Política Nacional de Atenção à Pessoa Idosa no Brasil. In: FREITAS, Elizabete Viana et al (Org.). Tratado de geriatria e gerontologia. Rio de Janeiro: Guanabara Koogan, 2002.

CRESWELL, John W. Projeto de pesquisa: métodos qualitativos, quantitativos e misto. Porto Alegre: Artmed, 2007.

DE VITTA, V. Atividade física e bem-estar na velhice. In: NERI, A. L \& FREIRE, S. A. (Orgs.). E por falar em boa velhice. Campinas: Papirus, 2000.

DEBERT, Guita Grin. A reinvenção da velhice: socialização e processos de reprivatização do envelhecimento. São Paulo: FAPESP, 1999.

EDITORA CORTEZ. Disponível em: <http://www.cortezeditora.com.br>. Acesso em 4 de maio de 2008. 
GUIMARÃES, R. M. Viver mais e melhor. In: Revista Humanidades: Terceira Idade, 46, 96-102, 1999.

IAMAMOTO, Marilda Villela. Serviço Social em tempo de capital fetiche: capital financeiro, trabalho e questão social. São Paulo: Cortez, 2007.

IBGE (Fundação Instituto Brasileiro de Geografia e Estatística). Censo Demográfico: Brasil, 2000. Rio de Janeiro: IBGE, 2000.

KARSH, Ursula M. Cuidadores familiares de Idosos: parceiros da equipe de saúde. In: Revista Serviço Social \& Sociedade, nº 75. Ano XXIV. São Paulo: Cortez, 103-113, 2003.

MASCARO, Sonia. O que é velhice? São Paulo: Brasiliense, 1997.

MINAYO, Maria Cecília de Souza (Org). Pesquisa social: teoria, método e criatividade. $25^{\mathrm{a}}$ ed. revista e atualizada. Petrópolis, RJ: Vozes, 2007.

ORGANIZAÇÃO DAS NAÇÕES UNIDAS (ONU). Envelhecimento ativo: uma política de saúde. Tradução Suzana Gontijo. Brasília: Organização Pan-Americana da Saúde, 2005.

PAPALÉO NETTO, M. O Estudo da Velhice no Século XX: Histórico, Definição do Campo e Termos Básicos. In: FREITAS, Elizabete Viana et al (Org.). Tratado de geriatria e gerontologia. Rio de Janeiro: Guanabara Koogan, 2002.

PEREIRA, Potyara A. P. Formação em Serviço Social, Política Social e o fenômeno do envelhecimento. Disponível em:

<http;//www.portaldoenvelhecimento.net/download/formacaosocialpotyara.pdf.>. Acesso em: 28 de Abril de 2008.

PLATAFORMA LATTES. Disponível em: <http://lattes.cnpq.br>. Acesso em: 10 de maio de 2008.

SILVA, Maria Ozanira da Silva e. Contribuições da revista para a construção do Serviço Social brasileiro. In: Revista Serviço Social \& Sociedade, $n^{\circ}$. 61. Ano XX. São Paulo: Cortez, 11-62, 1999.

VERAS, Renato Peixoto. País jovem com cabelos brancos: A saúde do idoso no Brasil. Rio de Janeiro: Relume Dumará, 1994.

A longevidade da população: desafios e conquistas. In: Revista Serviço Social \& Sociedade, $\mathrm{n}^{\circ}$. 75. Ano XXIV. São Paulo: Cortez, 5-18, 2003.

YASBEK, Maria Carmelita; SILVA, Maria Ozanira Silva e. Das origens à atualidade da profissão: a construção da Pós-graduação em Serviço Social. In: CARVALHO, Denise 


\section{ANEXO 1 \\ ROTEIRO DE ANÁLISE DOS ARTIGOS DA REVISTA SERVIÇO SOCIAL \& SOCIEDADE}

\section{Sobre o artigo:}

1. Nome do artigo:

2. Autor 1:

3. Autor 2:

4. Autor 3:

5. Outros autores:

6. Resumo do artigo:

7. Palavras-chave do artigo:

8. Número de páginas:

( ) Menos que 10 páginas

( ) Entre 15 e 20 páginas

( ) Entre 10 e 15 páginas

( ) Mais que 20 páginas

9. Metodologia utilizada na pesquisa do artigo

( ) Pesquisa teórica

( ) Entrevista

( ) Análise documental

( ) Estudo de caso

( ) Questionário

( ) Outros:

10. O artigo trata de saúde, assistência social ou previdência social?
( ) $\mathrm{Sim}$
( ) Não

\section{Sobre a Revista:}

1. Número da Revista:

2. Tema da Revista:

3. Ano de publicação:

4. Quantidade de artigos publicados na Revista: 
Sobre os autores:

\begin{tabular}{|l|l|l|l|l|}
\hline Autor / Sexo & $\begin{array}{c}\text { Formação } \\
\text { acadêmica }\end{array}$ & $\begin{array}{c}\text { Pós- } \\
\text { graduação }\end{array}$ & $\begin{array}{c}\text { Vínculo } \\
\text { institucional }\end{array}$ & Região / Estado \\
\hline & & & & \\
\hline & & & & \\
\hline & & & & \\
\hline & & & & \\
\hline
\end{tabular}




\section{ANEXO $2^{7}$ RESUMO DOS ARTIGOS PESQUISADOS}

\section{Artigo: A longevidade da população: desafios e conquistas}

\section{Autor: Renato Veras}

A repercussão médica e social da longevidade da população é discutida neste artigo. A partir das informações dos órgãos oficiais, são apresentados alguns fatores que levam a uma maior proporção da mulher idosa na sociedade, e são apresentadas as consequiências da solidão no final da vida. A influência dos processos da transição demográfica e epidemiológica na vida do idoso em uma sociedade heterogênea e com desigualdades sociais observadas no Brasil é discutida com grande ênfase no texto. Os novos modelos e conceitos da área da saúde e a preocupação crescente com os custos na assistência à saúde do idoso encerram este texto, em que se buscou apresentar um mosaico de questões que devem fazer parte das preocupações dos profissionais de saúde e das agendas de trabalho das autoridades competentes do país.

Palavras-chave: longevidade, transição demográfica, saúde do idoso.

\section{Artigo: Cidadania não tem idade}

Autora: Marta Regina Pastor Bruno

O presente artigo demonstra a possibilidade de se promover a educação para cidadania em qualquer etapa da vida do ser humano. Desafio particularmente interessante, quando enfrentado junto idoso, envolvendo-o num processo de aprendizado onde ele seja incentivado e instrumentalizado para assumir o papel de protagonista na busca de seu espaço social.

A velhice como categoria construída socialmente, pode sofrer transformação, gerando uma nova condição para essa etapa da vida do ser humano, sendo que um novo cenário

7 Os resumos foram extraídos das revistas Serviço Social \& Sociedade $\mathrm{n}^{\mathrm{o}} 75$ e 93. Os demais artigos não apresentam resumo. 
poderá se desenhar com a prática de atitudes como o cultivo de uma cultura de tolerância, onde o respeito às diferenças seja o valor fundamental e a consideração do Ser Humano como prioridade absoluta, independente da faixa etária, na efetivação de políticas públicas que busquem garantir a inclusão social para todos.

Palavras-chave: cidadania, velhice.

\section{Artigo: Conselho do Idoso como espaço público}

Autora: Sônia Mercedes Lenhard Bredemeier

Este trabalho apresenta uma argumentação teórica que parte de uma pesquisa, fundamentando a tese de que um conselho municipal amplia o espaço público para o idoso. Considerando aspetos relacionados à democracia, federalismo e descentralização, situa o conselho enquanto espaço público com o apoio das idéias de Arendt sobre este mesmo espaço, caracterizando a efetivação do conselho enquanto lócus da visibilidade/aparecimento, discurso e ação. Refere também a presença do assistentesocial neste campo de trabalho. Apresenta os conselhos enquanto lugares de uma prática democrática através dos dados levantados na pesquisa. A mesma foi realizada tendo como fonte, as datas registradas durante os dez anos de um conselho do idoso, através da análise de conteúdo. Conclui mencionando as dificuldades e apontando possíveis caminhos para a superação das mesmas.

Palavras-chave: democracia, federalismo, descentralização, espaço público e conselhos.

\section{Artigo: Crônica de viagem: um passeio por instituições asilares orientais}

\section{Autoras: Maria Helena Villas Boas Concone}

\section{Chiou Ruey Ling}

A presente crônica mostra uma pequena investida em outras formas de instituição desenvolvidas do outro lado do mundo. Muito haveria de dizer dos modos chineses de 
lidar com o envelhecimento. Apesar de o sistema asilar, isto não eliminou inteiramente a tradição chinesa do lugar de idoso na família.

Palavras-chave: instituição asilar, envelhecimento, cultura.

\section{Artigo: Cuidadores familiares de idosos: parceiros da equipe de saúde} Autor: Ursula Margarida Karsch

A grande maioria da população idosa no Brasil, hoje, mantém plena capacidade funcional por muito além dos sessenta. Em contrapartida, a idade é o maior fator de risco para as doenças degenerativas. Sabe-se que a maior parte dos idosos portadores de incapacidades físicas e mentais está em suas casas, na dependência de uma pessoa da família, que vem desempenhando a ajuda cotidiana nas atividades de vida diária, mesmo sem informação e orientação. Novos programas de assistência no domicílio vêm sendo desenvolvidos no Brasil, como o Programa Saúde da Família e as mais variadas formas de "home-care". Estas iniciativas, contudo, não estão envolvendo o cuidador do idoso dependente como um parceiro das equipes profissionais de saúde, assim como não estão atentas aos fatores de risco para a capacidade funcional do idoso residente com sua família.

Palavras-chave: idosos com dependência; cuidadores familiares; assistência domiciliar; envelhecimento.

\section{Artigo: Envelhecimento populacional: uma conquista para ser celebrada}

Autora: Marília Anselmo Viana da Silva Berzins

Este artigo trata do recente processo do envelhecimento populacional mundial e concentra-se nos dados estatísticos da população brasileira, procurando caracterizar o perfil de quem são, quantos, onde vivem e moram os sujeitos maiores de 60 anos. $\mathrm{O}$ conteúdo do texto chama a atenção para o crescente número de idosos e a necessidade do estabelecimento de políticas públicas para atender às suas necessidades. 
Palavras-chave: envelhecimento, dados estatísticos, Brasil.

\section{Artigo: Espaços internos e externos do corpo: envelhecimento e autonomia} Autor: Pedro Paulo Monteiro

Baseado na experiência profissional do autor como fisioterapeuta, o presente artigo visa discutir a respeito dos espaços, não apenas os externos, nos quais vivem os velhos em nossa sociedade, mas, principalmente, os internos, ou seja, os espaços de independência e autonomia do corpo. Um corpo sem autonomia é um corpo que nada decide, não possui escolhas sobre onde vai residir, vivendo em lugares contraídos e sem possibilidades. Portanto, se o velho consegue resgatar a autonomia de seu corpo, ele poderá estar aberto ao aprendizado existencial que lhe mantém a vida, porque viver é um processo contínuo de aprendizado, sendo o envelhecimento uma consequiência desse fenômeno existencial; ele estará livre para experimentar o diálogo intergeracional que lhe proporciona a unificação do seu tempo vivido com o tempo vivido dos mais jovens, formando um único e verdadeiro tempo: o da experiência de qualidade.

Palavras-chave: corpo, espaço de moradia, tempo, envelhecimento, autonomia.

\section{Artigo: Idosos: o medicamento intermediando relações}

Autora: Ruth Gelehrter da Costa Lopes

As informações e análises aqui apresentadas visam rastrear os componentes da saúde na velhice até chegar à problemática da ingestão das drogas medicamentosas. A questão ético-moral no consumo e prescrição de medicamentos envolvem a complexa relação entre profissionais da saúde e usuários idosos que, associada a pouca eficiência dos serviços, passa a corroborar para a automedicação.

Palavras-chave: saúde na velhice, automedicação, relação profissional e idoso. 


\section{Artigo: Modernidade e velhice}

Autora: Vera Lúcia Valsecchi de Almeida

Sob o signo da modernidade, a periodização da vida em etapas claramente demarcadas caminhou ao lado da identificação entre velhice e degeneração, decrepitude. Alçada à condição do "outro", ou da diferença a ser negada e afastada dos olhos e do pensamento, à velhice foi destinado um lugar muito pouco confortável, sinônimo de recusa e banimento. Das múltiplas formas assumidas pela negação da velhice, e considerando o importante lugar ocupado pelas imagens visuais no modelo da sociedade tornado hegemônico a partir do século XIX, este artigo explora tanto a expropriação dos idosos da condição referente do ato fotográfico, como a apropriação imagética destes para a reposição e atualização dos significados que recobrem a velhice, na atualidade.

Palavras-chave: velhice, modernidade, imagens visuais.

\section{Artigo: $O$ valor da atividade não remunerada realizada por pessoas maiores}

\section{de sessenta anos}

Autora: Viviam C. Herrero Lemos

O presente artigo traz uma investigação a respeito dos ganhos proporcionados pela atividade não remunerada realizada por pessoas maiores de sessenta anos, com ênfase no aspecto econômico envolvido. Foi baseado em pesquisa que objetivou uma análise socioeconômica do sentido e de resultados alcançados através de serviços realizados pelo segmento idoso, da qual foi possível extrair um valor em dinheiro que representa algumas das tantas contribuições dadas por essas pessoas em benefício de suas respectivas famílias e/ou comunidades.

Palavras-chave: atividade, envelhecimento, valor econômico.

\section{Artigo: Resiliência: um enfoque para a promoção de saúde em idosos}

Autora: Ana Valéria Rodrigues

Neide Cordeiro de Magalhães 
O objetivo deste trabalho é discutir as políticas públicas direcionadas aos idosos, tendo como foco a estimulação da resiliência, cujo conceito está pautado na capacidade de as pessoas se saírem fortalecidas de situações adversas e que as deixam vulnerabilizadas. Na história de vida de cada um, ocorrem perdas. Essas perdas são ainda maiores quando nos aproximamos da terceira idade, porque neste momento temos perda do vigor físico, e grande parte de nossa memória pode estar comprometida. Entretanto, é possível promover resiliência e ter uma vida saudável. Neste sentido as políticas direcionadas à terceira idade têm um papel fundamental na promoção da resiliência, uma vez que podem ampliar o autoconhecimento e promover o autocuidado.

Palavras-chave: Políticas públicas; resiliência, envelhecimento bem-sucedido.

\section{Artigo: Velhice: a identidade estigmatizada}

Autora: Elisabeth F. Mercadante

Este artigo analisa como é construída culturalmente a identidade social do idoso. Nela, as qualidades atribuídas aos velhos são amplas, gerais e chamam a atenção para características negativas que passam a defini-los como sujeitos vivendo situações de declínio tanto física quanto socialmente. São destacados, no presente artigo, o corpo, o trabalho, e a família como elementos importantes para a análise da identidade do idoso.

Palavras-chave: velho, identidade, corpo, trabalho e família. 